\title{
Green Synthesis of Biobased P-N Coating Via Mechanochemistry Strategy: For High-Eficiency Flame Retardant Finish of Cotton Fabric
}

\section{Junxiu Piao}

Qingdao University of Science and Technology

Jinyong Ren

Qingdao University of Science and Technology

\section{Yaofei Wang}

Qingdao University of Science and Technology

\section{Tingting Feng}

Qingdao University of Science and Technology

\section{Yaxuan Wang}

Qingdao University of Science and Technology

Wei Liu

Qingdao University of Science and Technology

Huixin Dong

Qingdao University of Science and Technology

\section{Wenjiao Chen}

Qingdao University of Science and Technology

Chuanmei Jiao

Qingdao University of Science and Technology

Xilei Chen ( $\nabla$ xichen@qust.edu.cn )

Qingdao University of Science and Technology

\section{Research Article}

Keywords: Flame retardant, Cotton fabric, Bio-based material, Mechanochemistry, Green chemistry

Posted Date: August 16th, 2021

DOl: https://doi.org/10.21203/rs.3.rs-782068/v1

License: (c) (i) This work is licensed under a Creative Commons Attribution 4.0 International License.

Read Full License 


\section{Abstract}

Cotton fabric is widely used in many occasions, but it is flammable with high fire risk. To meet the great fire safety demands of cotton fabric, a novel lignocellulosic-based P-N synergistic (LFPN) flame-retardant coating with high efficiency and environment friendly was developed via mechanochemistry strategy in the aqueous phase. The characterisation results showed the stable P-O-C bond formed to bind both lignocellulosic fibre and ammonium polyphosphate (APP). Meanwhile, LFPN has an excellent dispersion in water with a nanometer-scale enveloping rod structure. The cotton fabric treated by the LFPN coating showed outstanding flame-retardant properties, the peak heat release rate (PHRR) was reduced by $77 \%$ and the residue mass was increased by $259 \%$ compared with control cotton fabric. And there was a selfextinction phenomenon during the flammability test of flame retardant cotton. Based on the analysis of the combustion and pyrolysis process, a gas-condensed two-phase flame retardant mechanism model was proposed, which could be used to explain the action process of LFPN for cotton fabric during combustion.

\section{Introduction}

Natural cotton fabric with good performance is widely used in clothing, ornamentation, industrial fabrics, and further fields, due to hydrophilicity, air permeability, heat preservation and light resistance and other advantages (Wan et al., 2020; de Oliveira et al., 2021). However, cotton fabric has the drawback of flammability, especially the remarkable fire spreading characteristic, which poses a great threat to life, health, property safety, and in turn restricts the usage of cotton fabric in more scenarios (Alongi and Malucelli, 2015; Y. C. Li et al., 2011; Islam and van de Ven, 2021). So, it is urgent to reduce the fire risk of cotton fabric and furtherly broaden the application fields for cotton fabric (Wan et al., 2021; Y. Chen et al., 2021).

According to the reports that the flame-retardant treatment was an effective technique to reduce the fire risk for cotton fabric. Now, many kinds of flame retardants have been developed for cotton fabric, such as halogen (M. M. Zhang et al., 2016a; Dasari et al., 2013; Lu and Hamerton, 2002), phosphorus (Velencoso et al., 2018; He et al., 2020), nitrogen (Salmeia et al., 2016; Lu and Hamerton, 2002), inorganic compounds(Islam and van de Ven, 2021; Nabipour et al., 2020), and nano flame retardants (Bourbigot et al., 2010; He et al., 2020). Despite there are many effective flame retardants, some of the common flame retardants may be harmful to human beings and environment both in the manufactured and applicated stages (X. M. Zhang et al., 2016b; van der Veen and de Boer, 2012; Q. W. Wang et al., 2015). In particular, the halogen flame retardants release noxious halogen gases during the combustion process (Huang et al., 2019). Therefore, it is very necessary to carry out novel halogen-free and environmentally friendly flame retardants for cotton fabric.

In order to solve these environmental safety issues, the exploration of environment-friendly bio-based flame retardants has aroused great interests, such as chitosan, starch, and cyclodextrin (Costes et al., 2017). Especially, lignocellulosic biomass such as cellulose (Niu et al., 2020; Zheng et al., 2019), 
hemicellulose (L. Y. Zhang et al., 2020a; P. P. Li et al., 2019), and lignin (Yang et al., 2020) has been used to prepare various bio-based flame retardants, which has the characteristics of the wide source, low-cost, and renewable as the most abundant biomass resources on the earth(Dhyani and Bhaskar, 2018).

Lignocellulosic biomass-based flame retardants have thr inherent carbonization ability to produce stable char residue during the combustion process (Costes et al., 2017). However, there are still some issues of inefficiency, poor compatibility, and so on for these natural flame retardants. Lignocellulosic biomass is benefited from abundant hydroxyl groups reactive sites (Laurichesse and Averous, 2014) can obtain better flame retardant properties by flame-retardant modification, especially phosphorous and nitrogenfunctionalized modify by solution method (Yang et al., 2020; Zhu et al., 2020; Ding et al., 2016).

Recently, mechanochemistry has become an alternative for modifying natural biomass (T. L. Zhang et al., 2020c; T. L. Zhang et al., 2020b; P. P. Li et al., 2019), which can effectively reduce the use of solvents, improve the efficiency of modification, and separate complex biomass (Fiss et al., 2019). However, organic solvents, catalysts, phosphoric acid, or phosphoric anhydride are often used in the process of mechanochemistry modification to create reaction conditions, which is contrary to the original intention of using environment-friendly biomass flame retardant. Therefore, if we can use the characteristics, which can increase the temperature and pressure of the environment, of wet ball milling to create reaction conditions (Friscic et al., 2020; Andersen and Mack, 2018). The above problems may be improved and green preparation can be realized. At present, the use of the mechanochemistry approach in the aqueous phase to phosphorus and nitrogen functionalize of biomass is rarely reported.

In this work, the phosphorus-nitrogen functionalized lignocellulosic fibre (LFPN) flame-retardant coating had been synthesized, which used lignocellulosic fibre as lignocellulosic biomass, environment-friendly ammonium polyphosphate as phosphorus and nitrogen source, and deionized water as grinding aid, via mechanochemistry in aqueous phase approach. Then, the flame retardant finishing of cotton fabric was carried out by LFPN flame-retardant coating via the chemical grafting treated method. This bio-based coating endowed cotton fabrics with low-cost, high efficiency, and environmental flame retardant properties.

\section{Experimental}

\section{Materials}

Cotton fabric (pure cotton, $160 \mathrm{~g} / \mathrm{cm}^{2}$ ) was from Wen'an Hongda Weaving Co., Ltd (China). Lignocellulosic fibre (LF, B-300) was from Shanghai Crear Chemical Technology Co., Ltd (China). Ammonium polyphosphate (APP) was from Rhawn Co., Ltd (China).

\section{Synthesis of LFPN coating}

LFPN was prepared by ball milling, and ball-mill QM-3SP2 used was provided by Nanjing Chi Shun Technology Development Co., Ltd. Lignocellulosic fibre (31.25g), ammonium polyphosphate $(62.5 \mathrm{~g})$ and deionized water $(300 \mathrm{~mL})$ were added into a $500 \mathrm{~mL}$ stainless-steel jar with $750 \mathrm{~g}$ of stainless-steel balls at 
room temperature. The mill process was planned to run with a five min rest each $40 \mathrm{~min}$ at $30 \mathrm{~Hz}$, and the total milling time was set as $10 \mathrm{~h}$. The resultant mixture after milling was collected. And the product was centrifuged at $5000 \mathrm{r} / \mathrm{min}$ for $20 \mathrm{~min}$ to separate macromolecular chain and impurity solids. Finally, the saffron yellow supernatant with $4 \%$ LFPN was collected. The synthesis of LFPN coating was shown in Fig. 1.

\section{Flame retardant finishing of cotton fabric}

The cotton fabric, which was rinsed and dried in advance, was immersed in the suspension containing LFPN of a certain concentration (i.e., $0.5 w t \%, 1 w t \%, 2 w t \%$, and $4 w t \%$ ). This process was carried out at 60 ${ }^{\circ} \mathrm{C}$ for 2 hours. And the treated cotton fabric was taken out to dry at $80{ }^{\circ} \mathrm{C}$ until to constant weight. The obtained cotton fabric was labelled as Cotton-LFPN-1 with 0.72 wt\% LFPN, Cotton-LFPN-2 with 1.73 wt\% LFPN, Cotton-LFPN-3 with 3.18 wt\% LFPN, and Cotton-LFPN-4 with 6.87 wt\% LFPN, respectively.

Materials characterization was shown in supporting information.

\section{Results And Discussion}

\section{Structure and morphology analysis of LFPN}

TEM and SEM-EDS were applied to characterize the structure and morphology of LFPN, which was shown in Fig. 2. As shown in Fig. 2A, there were many nanometer particles, which were irregular sphere shapes, assembled around a certain structure became a cluster. In order to further explore the internal form of the cluster, TEM was carried out to get a 2D image of LFPN (Fig. 2b, c). Some rod nanofibres can be clearly observed with the width of 50-105 nm, and were coated with a lot of nanometer particles. It can be seen from the Fig. 2c, irregular spherical particles were uniformly scattered on its surface, forming clusters. The phenomenon explains the aggregation of nanometer particles in the SEM image of LFPN. Figure $2 d$ shows the chemical element distribution of LFPN by SEM-EDS image. The distribution of carbon elements showed a rod-like structure like TEM images, and phosphorus and nitrogen elements distributed evenly around carbon. Therefore, the possible structure of LFPN is the grafting of ammonium polyphosphate onto the surface of nanometer lignocellulosic fibres cut by shear force.

\section{Chemical structure analysis of LFPN}

The chemical composition and structure of LFPN were analyzed by FTIR, XRD, TGA, XPS, and dispersion stability test as shown in Fig. 3, respectively.

The FTIR spectra of LF, APP, and LFPN was shown in Fig. 3a. As for LF, the peaks at $1430 \mathrm{~cm}^{-1}$ and 1032 $\mathrm{cm}^{-1}$ were typical bands of $-\mathrm{OH}$ and $\mathrm{C}-0$ stretching, respectively (Hejna et al., 2020). The peaks at 1072 $\mathrm{cm}^{-1}(\mathrm{P}-\mathrm{O})$ and $1246 \mathrm{~cm}^{-1}(\mathrm{P}=0)$ were typical peaks of ammonium polyphosphate (Prabhakar et al., 2019). In the FTIR spectrum of LFPN, it can be seen not only characteristic peaks of APP at $1242 \mathrm{~cm}^{-1}$ $(P=0)$ and $1430 \mathrm{~cm}^{-1}(\mathrm{~N}-\mathrm{H})$ (Prabhakar et al., 2019) but also the characteristic peak of LF at $1032 \mathrm{~cm}^{-1}$ 
(C-O). More importantly, there were two new peaks at $1078 \mathrm{~cm}^{-1}$ and $511 \mathrm{~cm}^{-1}$ attributed to P-O-C (Zeng et al., 2020; Wan et al., 2020; T. L. Zhang et al., 2020c). Interestingly, compared to APP, the peak strength of LFPN at $1687 \mathrm{~cm}^{-1}(\mathrm{~N}-\mathrm{H})$ and $1430 \mathrm{~cm}^{-1}(\mathrm{~N}-\mathrm{H})$ is significantly reduced (Cai et al., 2018). The results can explain the phenomenon after ball milling: a strong smell of ammonia can be smelled when the lid of the ball mill jar was opened. Overall, the FTIR spectra revealed a possibility that crosslinking type APP was reacted with the hydroxyl group on LF to form the P-O-C bond.

The XRD patterns of LF, LFPN, and APP were shown in Fig. 3b. There were typical and sharp peaks of APP ad LF, indicating both APP and LF have good crystallinity. However, the XRD pattern of LFPN showed an amorphous crystal form, which was completely distinct from LF and APP. This characteristic of LFPN is consistent with the results of SEM and TEM images. The XRD images showed that amorphous morphology was due to the encapsulation of clusters of particles. And it is proved that LFPN has a smaller particle size than LF or APP. Moreover, only weak peaks at $15.7^{\circ}$ and $29.8^{\circ}$ were corresponding to the characteristic peaks of LF and APP, respectively. In conclusion, LFPN was obtained by the chemical reaction between lignocellulosic fibre and ammonium polyphosphate

The XPS survey spectra were also used to characterize the structure of LFPN as shown in Fig. 3e. And, the peaks ascribed to $01 \mathrm{~s}, \mathrm{~N} 1 \mathrm{~s}, \mathrm{C} 1 \mathrm{~s}$, and P2p can be easily found. What needs illustration is that the peak at $346.0 \mathrm{eV}$ was assigned to $\mathrm{Ca} 2 \mathrm{p}$, which was introduced during the production and treatment of LF (Dhyani and Bhaskar, 2018). The above results indicated that there were C, O, P, N elements for LFPN, which was the sum of the elements in both LF and APP.

The P2p spectra of LFPN can be divided into double peaks at $134.0 \mathrm{eV}(\mathrm{P}-\mathrm{O}-\mathrm{C})$ and $132.9 \mathrm{eV}(\mathrm{P}=\mathrm{O})(\mathrm{T}$. L. Zhang et al., 2020c; T. L. Zhang et al., 2020b), as shown in Fig. 3f. The appearance of $P=0$ and P-O-C bonds indicated that there was a new chemical bond formed by the reaction between ammonium polyphosphate and LF. For LFPN and APP, it should be figured out there were two subpeaks at $400.7 \mathrm{eV}$ for $\mathrm{NH}_{4}{ }^{+}$and at $398.5 \mathrm{eV}$ for $-\mathrm{NH}$ - in the $\mathrm{N} 1 \mathrm{~s}$ spectra, respectively(P. K. Zhang et al., 2018). However, there were many differences for the two subpeaks between LFPN and APP. Firstly, the ratio of $\mathrm{NH}_{4}^{+}$to $-\mathrm{NH}-$ content in APP is 1.55, while the ratio in LFPN is 6.46. Secondly, the peak intensity of N1s for LFPN was $30 \%$ lower than that of APP. Lastly, the P/N atomic ratio of LFPN is about 1.00 , which is two times higher than that of APP. The above three points indicated that the chains of cross-linked APP were broken by the action of shear force in the process of the mill, greatly reducing the $-\mathrm{NH}$ - and some of the $\mathrm{NH}_{4}{ }^{+}$undergo hydrolysis, making APP with a small molecular chain react with the hydroxyl group in LF, and increasing the $\mathrm{P} / \mathrm{N}$ atomic ratio in LFPN.

The transparent orange LFPN suspension showed good dispersion and stability in water (Fig. 3d). And there were no particles felled down after 24 hours. This phenomenon can be illustrated by two reasons: one is that LFPN has a smaller molecular weight than both APP and LF; the other is the introduction of hydrophilic groups such as phosphate groups into LF (Zabihi et al., 2020). 
By combining SEM, TEM, FTIR, XRD, XPS, and dispersion stability test, the reaction mechanism can be speculated in Fig. 1. A long time and intermittent ball milling make the chains of LF and APP break into small molecules and release gases such as ammonia and water vapor, which results in a pressure increase in the jar. At the same time, the physical impact of the ball mill produces a lot of heat, and due to the heat dissipation ability of the stainless-steel jar is not as good as the agate jar, the temperature in the jar continuously increased. It can be easily verified by the boiling phenomenon after ball milling. It is easy that the multi-hydroxyl LF can react with APP to generate LFPN flame retardant with short-chain biobased phosphate ester in an environment of high temperature, high pressure, and strong shear force.

The thermal stability of LF, APP, and LFPN was analyzed by TGA. The TGA results of the samples under nitrogen atmosphere were carried out as Fig. 3c. The thermal degradation of APP proceeds by two stages: the temperature of the first stage is between $300-500{ }^{\circ} \mathrm{C}$, which is due to the release of $\mathrm{NH}_{3}$ accompanied by the formation of polyphosphoric acid; the other stage is between $500-700{ }^{\circ} \mathrm{C}$, corresponding to volatilization of metaphoric acid and $\mathrm{P}_{2} \mathrm{O}_{5}$ (Prabhakar et al., 2019; Sun et al., 2013; P. K. Zhang et al., 2018). There were three main degradations in $200-750{ }^{\circ} \mathrm{C}$ of LF: the first stage between $200-310{ }^{\circ} \mathrm{C}$ was due to pyrolysis of hemicellulose; the second stage between $310-400{ }^{\circ} \mathrm{C}$ was caused by pyrolysis of cellulose; the third stage between $200-750^{\circ} \mathrm{C}$ was corresponding to the disintegration of lignin through a wide temperature range (P. P. Li et al., 2019; Dhyani and Bhaskar, 2018; Ramirez-Estrada et al., 2021). As for LFPN, the pyrolysis process has some similarities with LF, but it is completely different. A weight loss was observed between $150-250^{\circ} \mathrm{C}$ of LFPN, indicating the release of initial phosphoric acid and escape of ammonia due to the introduction of low polymeric degree ammonium phosphate structure. And the degradation process between $220-550{ }^{\circ} \mathrm{C}$ was caused by the slow decomposition of cellulose, hemicellulose, and lignin. It is worth noting that, compared to the DTG curve of $L F$, the decomposition rate of LFPN was significantly reduced after $220^{\circ} \mathrm{C}$. This phenomenon may be that phosphoric acid promotes dehydration and cross-linking of P-O-C bond linked lignocellulosic fibre to carbon formation. And the inference can be confirmed by the initial decomposition temperature $\left(T_{5 \%}\right)$. $\mathrm{T}_{5 \%}$ of APP, LF and LFPN were $348.1{ }^{\circ} \mathrm{C}, 319.4{ }^{\circ} \mathrm{C}$ and $236.9^{\circ} \mathrm{C}$, respectively. $\mathrm{T}_{5 \%}$ demonstrated that the introduction of the ammonium phosphate structure and the formation of P-O-C bond promote the early decomposition of ammonium polyphosphate and the cross-linking with LF to form carbon char. The formation of the carbon char layer significantly reduces the decomposition rate of LF, resulting in a higher final residual mass of LFPN.

In addition, it has been reported that the decomposition temperature for cotton fabric is about $250^{\circ} \mathrm{C}$. In contrast, the decomposition temperature of LFPN is lower than $250^{\circ} \mathrm{C}$, and LFPN has a good carbon formation effect, so it is very suitable for the flame retardant finishing of cotton fabric (Grancaric et al., 2017; Pakdel et al., 2020).

\section{Characterization of Cotton-LFPN}

SEM-EDS was used to survey the surface morphology of Cotton and Cotton-LFPN, as shown in Fig. 4. As displayed in Fig. 4, both Cotton and Cotton-LFPN showed typical smooth cotton fibre structure at low 
magnification. At the same time, many fine particles on the surface of cotton-LFPN at high magnification makes the surface rough. The EDS results of Cotton-LFPN (Fig. 4e) confirmed that the many small particles on the fabric surface were due to the formation of LFPN flame-retardant coating.

To understand the form of LFPN coating on the cotton surface, XRD and ATR-FTIR were used to study the fabric surface, which was shown in Fig. 5.

As is shown in Fig. 5a, XRD patterns of Cotton and Cotton-LFPN both showed the typical peaks of cotton fabric. The difference lies in the intensity of the diffraction peak. The peak strength of Cotton-LFPN is weaker than that of Cotton, indicating that there is a thin film composed of amorphous material on the surface of cotton fabric. The phenomenon is corresponding to Fig. 4 and Fig. 3b.

As shown by ATR-FTIR spectra in Fig. 5b, most peaks of Cotton-LFPN were similar to those of Cotton, except the new peaks of $\mathrm{N}-\mathrm{H}, \mathrm{P}=\mathrm{O}$, and $\mathrm{P}-\mathrm{O}$ at $1430 \mathrm{~cm}^{-1}, 1242 \mathrm{~cm}^{-1}$, and $878 \mathrm{~cm}^{-1}$, respectively (Bai et al., 2020). In particular, the peak strength of P-O is much stronger than it of LFPN at this wavenumber. This indicates that under the action of heating, the LFPN bonds with the hydroxyl group on the fabric to form a new P-O-C bond.

\section{Thermostability of cotton fabric}

The TGA curves for Cotton and Cotton-LFPN under $\mathrm{N}_{2}$ were presented in Fig. 6 , and the related data were summarized in Table 1. Both Cotton and Cotton-LFPN showed the evaporation of water before $110^{\circ} \mathrm{C}$. For Cotton, there was one main degradation process between 250 and $400{ }^{\circ} \mathrm{C}$, which was due to the thermal decomposition of cellulose (Lin et al., 2019; Costes et al., 2017; Y. Zhang et al., 2019). However, the pyrolysis of Cotton-LFPN was distinct from that of Cotton. As for the Cotton-LFPN compared with that of Cotton., the initial decomposition began about $38.8^{\circ} \mathrm{C}$ earlier, and the char residue was increased from $16.6 \%$ to $34.7 \%$, respectively. Moreover, the maximum decomposition rate of Cotton-LFPN decreased by $27 \%$, and the temperature at the maximum decomposition rate of Cotton-LFPN decreased from $359{ }^{\circ} \mathrm{C}$ to $296{ }^{\circ} \mathrm{C}$. Indicating that LFPN decomposed and formed a char layer, and then the phosphorus products after decomposition dehydrated cotton fabric into carbon char to inhibit further decomposition.

To sum up, the pyrosis of cotton-LFPN consists of two carbonization processes: one process is the formation of LFPN char layer with thermal insulation and shielding effect; the other process is the crosslinking carbonization process of cotton fabrics promoted by LFPN.

Table 1

TGA data of Cotton and Cotton-LFPN.

\begin{tabular}{|lllll|}
\hline Sample & $\mathrm{T}_{5 \%} /{ }^{\circ} \mathrm{C}$ & $\mathrm{T}_{\max } /{ }^{\circ} \mathrm{C}$ & $\mathrm{D}_{\max } /\left(\% /{ }^{\circ} \mathrm{C}\right)$ & Char residue at $700{ }^{\circ} \mathrm{C} / \mathrm{wt} \%$ \\
\hline Cotton & 271.9 & 359 & 1.26 & 16.6 \\
\hline Cotton-LFPN & 233.1 & 296 & 0.95 & 34.7 \\
\hline
\end{tabular}

Flame-retardant Performance Analysis 
In corresponding to investigate the flame retardant efficiency of LFPN for cotton fabric, the improved vertical flammability test (IVFT) and cone calorimeter test (CCT) were carried out, and the results were shown in Fig. 7.

As shown in Fig. 7a and video in the support information, both Cotton and Cotton-LFPN were ignited at 3 s, but showed a completely different combustion behavior. The flame height and fire spread speed of Cotton-LFPN were weaker than those of Cotton. Moreover, the flame was extinguished, which meant the end of combustion for Cotton-LFPN, while the smolder phenomena lasted for about 20 seconds of Cotton. Smoldering is extremely harmful to fire safety, especially for cotton fabrics. So, it is of great significance to eliminate the smoldering of cotton fabrics (Alongi and Malucelli, 2015; Hagen and Meyer, 2021; Wan et al., 2020). In addition, self-extinguishing of Cotton-LFPN occurred in the horizontal direction, and a dense carbon layer with less than 1/3 damaged area was formed. The IVFT results indicated the good flame-retardant performance of Cotton-LFPN and the excellent char residue-formation property of LFPN.

To further quantitatively analyze flame retardancy, CCT was carried out to study the combustion behavior of cotton fabrics (B. H. Yuan et al., 2017). And the results of CCT were shown in Fig. 7b, c, and Table 2, respectively. The peak heat release rate (PHRR) and total heat release (THR) values of Cotton-LFPN were significantly reduced with the gradual increasing load of LFPN, compared with Cotton. Especially, the PHRR and THR values of Cotton-LFPN-4 were reduced by $57.4 \%$ and $42.2 \%$ compared to those of the control cotton fabric, respectively. As for the smoke parameter, the smoke factor (SF, SF = PSPR $\times$ HRR) is an effective index to balance heat and smoke effect (X. L. Chen et al., 2017). From SF curves, it was obvious that a good effect on smoke suppression can be obtained for Cotton-LFPN. However, there was no obvious regularity of SF with different loading of LFPN. Especially for Coton-LFPN-2, the SF value was much higher than that of the control cotton fabric. This may be due to the crack of the surface charforming fabric, leading to the rapid escape of the isolated flue gas into flame zoom. As shown in Fig. 7c, in the case of Cotton-LFPN, there was a dense char residue layer formed, which can play a role as a physical barrier. In addition, the $\mathrm{CO}_{2}$ / $\mathrm{CO}$ ratio can reflect the combustion efficiency. With the increase of LFPN loads, the $\mathrm{CO}_{2} / \mathrm{CO}$ ratio decreased gradually, which means the combustion efficiency decreased gradually. This indicated that the formation of a cross-linking char layer made the burning more inadequate. Moreover, the mass loss curves correspond to thermal stability results and can be explained by digital images of char residue layer after CCT (Fig. 7c). Excellent char-formation performance can effectively reduce the generation of flammable volatiles gases to delay combustion and selfextinguishing behavior (P. P. Li et al., 2019).

The CCT results were closely related to IVFT and showed the same effect, which indicated that cottonLFPN has excellent flame-retardant performance and flame retardant efficiency. 
Table 2

CCT data of Cotton and Cotton-LFPN.

\begin{tabular}{|lllllll|}
\hline Sample & $\begin{array}{l}\mathrm{TTI} / \\
\mathbf{s}\end{array}$ & $\begin{array}{l}\mathrm{PHRR} / \\
\left(\mathrm{kW} / \mathrm{m}^{2}\right)\end{array}$ & $\begin{array}{l}\mathrm{THR} / \\
\left(\mathrm{MJ} / \mathbf{m}^{2}\right)\end{array}$ & $\begin{array}{l}\mathrm{SF} / \\
\left(\mathrm{MW} / \mathrm{m}^{2}\right)\end{array}$ & $\begin{array}{l}\mathrm{CO}_{2} / \mathrm{CO} / \\
(\mathbf{g} / \mathbf{g})\end{array}$ & $\begin{array}{l}\text { Residue/ } \\
\mathbf{w t} \%\end{array}$ \\
\hline Cotton & 23 & 287.89 & 7.20 & 4.22 & 49.06 & 11.11 \\
\hline $\begin{array}{l}\text { Cotton- } \\
\text { LFPN-1 }\end{array}$ & 16 & 221.59 & 6.12 & 1.97 & 17.64 & 22.24 \\
\hline $\begin{array}{l}\text { Cotton- } \\
\text { LFPN-2 }\end{array}$ & 13 & 184.94 & 5.72 & 2.37 & 10.25 & 19.46 \\
\hline $\begin{array}{l}\text { Cotton- } \\
\text { LFPN-3 }\end{array}$ & 13 & 168.38 & 5.32 & 11.12 & 7.53 & 18.90 \\
\hline $\begin{array}{l}\text { Cotton- } \\
\text { LFPN-4 }\end{array}$ & 12 & 122.56 & 4.16 & 2.60 & 7.87 & 28.76 \\
\hline
\end{tabular}

\section{Flame Retardant Mechanism}

Condensed phase analysis. In order to deduce the flame-retardant mechanism of Cotton-LFPN, SEM, LRS and ATR-FTIR were used to investigate the structural change of condensed phase, as shown in Fig. 8.

As shown in Fig. 8d, the SEM image of char residues after CCT qualitatively confirmed the results of CCT. It was easily found that the fibre structure of char for Cotton was incomplete, exhibited relatively loose and fragile. In contrast, a compact char residue with a complete and tight fibrous structure obtained from Cotton-LFPN can effectively insulate flammable gas into oxygen and delay heat transfer (Y. Yuan et al., 2020). Specifically, some carbon tumors with spherical structure can be observed, indicating ductile char surface from the LFPN coating acted effective protection for cotton fabric from further combustion(Liu et al., 2016).

The LRS was conducted to further quantitative evaluation performance of char residues of Cotton and Cotton-LFPN after CCT, as depicted in Fig. 8a, b. The two strongly overlapping peaks at around 1580 (G) and 1350 (D) $\mathrm{cm}^{-1}$, which belonged to graphitized and amorphous carbon, respectively (Tao et al., 2021; Zhao et al., 2021). The proportion of the integral area of $D$ band and $G$ band $\left(I_{D} / I_{G}\right)$ can reflect the degree of graphitization for char residue. It means the lower $\mathrm{I}_{\mathrm{D}} / \mathrm{I}_{\mathrm{G}}$ signifies the higher graphitization and physical barrier performance(R. Chen et al., 2020). The $I_{D} / I_{G}$ value of Cotton-LFPN $\left(I_{D} / I_{G}=0.89\right)$ was lower than that of Cotton $\left(I_{D} / I_{G}=1.27\right)$, which means the graphitization degree of Cotton-LFPN is higher than that of Cotton. The results of LRS is corresponding to that of SEM.

Moreover, the char residues of Cotton-LFPN were analyzed by ATR-FTIR to speculate about the possible course of change of condensed phase. As shown in Fig. 8c, peaks at $1101 \mathrm{~cm}^{-1}$ assigned to the P-O-C bond, demonstrating the phosphor carbonaceous structure was formed by LFPN (Zeng et al., 2020). And characteristic absorption peak of C-O-C and C-H peaks were obtained at 1270 and $2950 \mathrm{~cm}^{-1}$ (Zheng et al., 2019), respectively. This indicated that there were carbonized into the char with cross-linked aromatic 
ring components. The analysis of the condensed phase showed the phosphate groups in LFPN catalyzed dehydration to form a crosslinked char protection layer, which played a good flame retardant effect.

Gas phase analysis. In addition to the condensed phase, the gas phase analysis can further understand the combustion and pyrolysis process and infer the flame-retardant mechanism.

Effective heat of combustion (EHC), which means the ratio of heat release rate to the mass loss rate, is a valid measure to judge the flame-retardant mechanism. Because EHC can show the degree of involvement for flammable volatile gases in the combustion process (Tang et al., 2016; Dong et al., 2016). The EHC curves of Cotton and Cotton-LFPN was given in Fig. 9. Compared with the control cotton fabric, the EHC of treated cotton fabric was significantly reduced. This indicated Cotton-LFPN produced less-flammable volatile gases and gas phase flame-retardant effect existed.

It has been reported that the microscale-combustion calorimeter was an effective method to vertify the result of EHC (Xing et al., 2009; Qian et al., 2016; H. X. Yuan et al., 2012). From Fig. 9b, the PHRR value of Cotton-LFPN was reduced by $77 \%$ than that of Cotton, indicating the Cotton-LFPN pyrolized flammable volatiels less than the control cotton fabric.

Therefore, TG-IR-GC/MS was conducted to analyze the change among the gas phase during pyrolysis (Yu et al., 2021), as shown in Fig. 10. The peak in $3746 \mathrm{~cm}^{-1}$ assigned to the $\mathrm{O}-\mathrm{H}$ bond of $\mathrm{H}_{2} \mathrm{O}$. And it was obvious that the peaks at $2359,2182,1732$, and $1506 \mathrm{~cm}^{-1}$ correspond to $\mathrm{CO}_{2}, \mathrm{CO}$ of the thermal cracking process, carbonyl compounds, and aromatic compounds, respectively. From the FTIR spectrum of gas products at maximum decomposition rate (Fig. 10a), combustible gas of Cotton-LFPN such as hydrocarbon and carbonyl compounds were decreased compared with control cotton fabrics. Nay, the TG-IR spectra at a specific temperature (Fig. 10b, c) of 100, 200, 300, 400, 500, 600 and $700{ }^{\circ} \mathrm{C}$ showed the intensity of pyrolysis gas for Cotton-LFPN is generally weaker than that for Cotton. Gas chromatogram (Fig. 10d) combined with mass spectrum can further confirm the infer of TG-IR. Compared with control fabrics, aldehydes, ketones, esters, and aromatic pyrolysis products of Cotton-LFPN were decreased except for the furans. This indicated that LFPN catalyzes the dehydration and carbonization of cotton fabrics, and inhibits the formation of L-glucose and the increase of pyrolysis products. It is also worth noting that the peaks at 3300,1625 , and $1500 \mathrm{~cm}^{-1}$, corresponding to the $\mathrm{NH}_{3}$ absorptions, can be observed from Fig. 10c (Z. Z. Wang et al., 2009). And significant enhancement of the water absorption peak. This indicated there was gas phase flame-retardant mechanism in LFPN.

Based on the above analysis, the flame-retardant mechanism of LFPN could be speculated, and the possible process as illustrated in Fig. 11. The flame-retardant mechanism of LFPN can be divided into two parts: condensed phase and gas phase. The condensed phase flame-retardant mechanism could be separated into two aspects. On the one hand, LFPN flame-retardant coating was dehydrated and cyclized into graphitization LFPN char layer at high temperature due to the polyhydroxy structure and phosphaterich group of LFPN. LFPN char layer was endowed with a dense protective layer with the carbon tumor structure, which can isolate the contact between oxygen and combustible gas, suppress released smoke, 
shield the transfer of heat. On the other hand, LFPN flame-retardant coating released phosphoric acid and derivatives, catalyzed the cross-linking carbonization of cotton fibres, and form a stable phosphoruscontaining ring structure, to prevent the further decomposition of cellulose. In the gas phase, the concentration of combustible gas was diluted by non-flammable gases such as $\mathrm{NH}_{3}$ and $\mathrm{H}_{2} \mathrm{O}$ vapor which was released by LFPN flame retardant coating. Moreover, the self-extinguishing phenomenon proved that LFPN decomposed $\mathrm{P}$. radicals which participated in the free radical competitive reaction and reduced the concentration of $\mathrm{OH} \cdot$ in the flame region (Velencoso et al., 2018).

\section{Conclusion}

In this work, a novel lignocellulosic-based P-N synergistic (LFPN) flame-retardant coating had been successfully green synthesized by mechanochemical approach with lignocellulosic fibre, ammonium polyphosphate, and water, without any organic solvent or organic auxiliaries. The LFPN had a nanometerscale enveloping rod structure which was riched in phosphorus and nitrogen elements. Meanwhile, the results of FTIR, XRD, and XPS showed the formation of the P-O-C bond and confirmed the chemical structure of LFPN. In addition, LFPN also had excellent thermal stability and water dispersion, which was confirmed by TGA and dispersion test. And the decomposition temperature of LFPN flame-retardant coating was matched with that of the cotton fabric. Therefore, cotton fabric was finished with LFPN flame-retardant coating. The layer of coating was fomed by LFPN flame-retardant coating on the surface of fabric through the chemical bonding. The PHRR, THR, SF, $\mathrm{CO}_{2} / \mathrm{CO}$, and damaged area of Cotton-LFPN was decreased by $57.4 \%, 42.2 \%, 38.4 \%, 84.7 \%$, and $66.7 \%$, respectively. And the residual mass of CottonLFPN increased by $109.3 \%$ compared to that of neat cotton fabric. The above results indicated that LFPNCotton has superior flame retardant properties. SEM-EDS, ATR-FTIR, LRS, EHC, MCC, and TG-IR-GC/MS were used to illustrate the condensed phase and gas phase change of Cotton-LFPN during combustion. Basing on the above analysis, the flame-retardant mechanism of Cotton-LFPN was deduced. As for the condensed phase flame-retardant mechanism, there were two processes of carbonization: one is that LFPN was dehydrated and carbonized under the action of high temperature due to the polyphosphate groups, formed a stable protective carbon char layer which plays a role in physical barrier; the other is that phosphoric acid was released during the thermal decomposition of LFPN, which catalyzed the crosslinked cyclization of cotton fabric and prevented the further decomposition of cotton fabrics to release flammable substances such as aldehydes, ketones, ethers, and esters. As for the gas phase flameretardant mechanism, LFPN released non-flammable gases such as $\mathrm{NH}_{3}$ and $\mathrm{H}_{2} \mathrm{O}$ which diluted the concentration of combustible gas in the combustion zone. Meanwhile, the production of $P$. radicals would interrupt the free radical reaction in the flame region. Thus, LFPN obtained through the green mechanization method with the environment-friendly, low toxicity, and high-efficiency flame retardant characteristics would have a broader application prospect.

\section{Declarations}

\section{Acknowledgment}


This work was supported by the National Natural Science Foundation of China (No. 51776101).

\section{Supplementary Information}

The materials characterization (PDF) and combustion video of Cotton and Cotton-LFPN (mp4).

\section{Ethics declarations}

\section{Conflicts of Interest}

The authors declare that they do not have any conflict of interest.

\section{Ethical approval}

This study does not include any studies conducted by any author on human participants or animals. The authors claim the compliance with the ethical standards.

\section{References}

1. Alongi, J., \& Malucelli, G. (2015). Cotton flame retardancy: state of the art and future perspectives. Rsc Advances, 5(31), 24239-24263. doi:10.1039/c5ra01176k.

2. Andersen, J., \& Mack, J. (2018). Mechanochemistry and organic synthesis: from mystical to practical. Green Chemistry, 20(7), 1435-1443. doi:10.1039/c7gc03797j.

3. Bai, K. K., Fan, J. C., Shi, P. H., Min, Y. L., \& Xu, Q. J. (2020). Directly ball milling red phosphorus and expended graphite for oxygen evolution reaction. Journal of Power Sources, 456. doi:ARTN 228003 10.1016/j.jpowsour.2020.228003.

4. Bourbigot, S., Samyn, F., Turf, T., \& Duquesne, S. (2010). Nanomorphology and reaction to fire of polyurethane and polyamide nanocomposites containing flame retardants. Polymer Degradation and Stability, 95(3), 320-326. doi:10.1016/j.polymdegradstab.2009.11.011.

5. Cai, X., Chen, H., Jiang, D., Pan, M. Z., \& Mei, C. T. (2018). The thermal property and flame retardancy of RPC with a polyelectrolyte complex of nanocrystalline cellulose and ammonium polyphosphate. Journal of Thermal Analysis and Calorimetry, 134(3), 2089-2096. doi:10.1007/s10973-018-7639-3.

6. Chen, R., Luo, Z. J., Yu, X. J., Tang, H., Zhou, Y., \& Zhou, H. (2020). Synthesis of chitosan-based flame retardant and its fire resistance in epoxy resin. Carbohydrate Polymers, 245. doi:ARTN 116530 10.1016/j.carbpol.2020.116530.

7. Chen, X. L., Wang, W. D., Li, S. X., \& Jiao, C. M. (2017). Fire safety improvement of para-aramid fiber in thermoplastic polyurethane elastomer. Journal of Hazardous Materials, 324, 789-796. doi:10.1016/j.jhazmat.2016.11.065.

8. Chen, Y., Liu, S. D., Wan, C. Y., \& Zhang, G. X. (2021). Facile synthesis of a high efficiency and durability L-citrulline flame retardant for cotton. International Journal of Biological Macromolecules, 166, 1429-1438. doi:10.1016/j.jbiomac.2020.11.022. 
9. Costes, L., Laoutid, F., Brohez, S., \& Dubois, P. (2017). Bio-based flame retardants: When nature meets fire protection. Materials Science \& Engineering R-Reports, 117, 1-25. doi:10.1016/j.mser.2017.04.001.

10. Dasari, A., Yu, Z. Z., Cai, G. P., \& Mai, Y. W. (2013). Recent developments in the fire retardancy of polymeric materials. Progress in Polymer Science, 38(9), 1357-1387. doi:10.1016/j.progpolymsci.2013.06.006.

11. de Oliveira, C. R. S., Batistella, M. A., Lourenco, L. A., de Souza, S. M. D. G. U., \& de Souza, A. A. U. (2021). Cotton fabric finishing based on phosphate/clay mineral by direct-coating technique and its influence on the thermal stability of the fibers. Progress in Organic Coatings, 150. doi:ARTN 105949 10.1016/j.porgcoat.2020.105949.

12. Dhyani, V., \& Bhaskar, T. (2018). A comprehensive review on the pyrolysis of lignocellulosic biomass. Renewable Energy, 129, 695-716. doi:10.1016/j.renene.2017.04.035.

13. Ding, H. Y., Wang, J. F., Wang, C. P., \& Chu, F. X. (2016). Synthesis of a novel phosphorus and nitrogencontaining bio-based polyols and its application in flame retardant polyurethane sealant. Polymer Degradation and Stability, 124, 43-50. doi:10.1016/j.polymdegradstab.2015.12.006.

14. Dong, C. H., Lu, Z., Zhang, F. J., Zhu, P., Wang, P., Che, Y., et al. (2016). Combustion behaviors of cotton fabrics treated by a novel nitrogen- and phosphorus-containing polysiloxane flame retardant. Journal of Thermal Analysis and Calorimetry, 123(1), 535-544. doi:10.1007/s10973-015-4914-4.

15. Fiss, B. G., Hatherly, L., Stein, R. S., Friscic, T., \& Moores, A. (2019). Mechanochemical Phosphorylation of Polymers and Synthesis of Flame-Retardant Cellulose Nanocrystals. Acs Sustainable Chemistry \& Engineering, 7(8), 7951-7959. doi:10.1021/acssuschemeng.9b00764.

16. Friscic, T., Mottillo, C., \& Titi, H. M. (2020). Mechanochemistry for Synthesis. Angewandte ChemieInternational Edition, 59(3), 1018-1029. doi:10.1002/anie.201906755.

17. Grancaric, A. M., Colleoni, C., Guido, E., Botteri, L., \& Rosace, G. (2017). Thermal behaviour and flame retardancy of monoethanolamine-doped sol-gel coatings of cotton fabric. Progress in Organic Coatings, 103, 174-181. doi:10.1016/j.porgcoat.2016.10.035.

18. Hagen, B. C., \& Meyer, A. K. (2021). From smoldering to flaming fire: Different modes of transition. Fire Safety Journal, 121. doi:ARTN 103292 10.1016/j.firesaf.2021.103292.

19. He, W. T., Song, P. A., Yu, B., Fang, Z. P., \& Wang, H. (2020). Flame retardant polymeric nanocomposites through the combination of nanomaterials and conventional flame retardants. Progress in Materials Science, 114. doi:ARTN 100687 10.1016/j.pmatsci.2020.100687.

20. Hejna, A., Sulyman, M., Przybysz, M., Saeb, M. R., Klein, M., \& Formela, K. (2020). On the Correlation of Lignocellulosic Filler Composition with the Performance Properties of Poly(epsilon-Caprolactone) Based Biocomposites. Waste and Biomass Valorization, 11(4), 1467-1479. doi:10.1007/s12649-0180485-5.

21. Huang, Y. B., Jiang, S. H., Liang, R. C., Liao, Z. W., \& You, G. X. (2019). A green highly-effective surface flame-retardant strategy for rigid polyurethane foam: Transforming UV-cured coating into 
intumescent self-extinguishing layer. Composites Part a-Applied Science and Manufacturing, 125. doi:ARTN 105534 10.1016/j.compositesa.2019.105534.

22. Islam, M. S., \& van de Ven, T. G. M. (2021). Cotton-Based Flame-Retardant Textiles: A Review. Bioresources, 16(2), 4354-4381. doi:10.15376/biores.16.2.Islam.

23. Laurichesse, S., \& Averous, L. (2014). Chemical modification of lignins: Towards biobased polymers. Progress in Polymer Science, 39(7), 1266-1290. doi:10.1016/j.progpolymsci.2013.11.004.

24. Li, P. P., Sirvio, J. A., Hong, S., Ammala, A., \& Llimatainen, H. (2019). Preparation of flame-retardant lignin-containing wood nanofibers using a high-consistency mechano-chemical pretreatment. Chemical Engineering Journal, 375. doi:ARTN 122050 10.1016/j.cej.2019.122050.

25. Li, Y. C., Mannen, S., Morgan, A. B., Chang, S. C., Yang, Y. H., Condon, B., et al. (2011). Intumescent AllPolymer Multilayer Nanocoating Capable of Extinguishing Flame on Fabric. Advanced Materials, 23(34), 3926-+. doi:10.1002/adma.201101871.

26. Lin, D. M., Zeng, X. R., Li, H. Q., Lai, X. J., \& Wu, T. Y. (2019). One-pot fabrication of superhydrophobic and flame-retardant coatings on cotton fabrics via sol-gel reaction. Journal of Colloid and Interface Science, 533, 198-206. doi:10.1016/j.jcis.2018.08.060.

27. Liu, C., Chen, T., Yuan, C. H., Song, C. F., Chang, Y., Chen, G. R., et al. (2016). Modification of epoxy resin through the self-assembly of a surfactant-like multi-element flame retardant. Journal of Materials Chemistry A, 4(9), 3462-3470. doi:10.1039/c5ta07115a.

28. Lu, S. Y., \& Hamerton, I. (2002). Recent developments in the chemistry of halogen-free flame retardant polymers. Progress in Polymer Science, 27(8), 1661-1712. doi:Pii S0079-6700(02)00018-7 Doi 10.1016/S0079-6700(02)00018-7.

29. Nabipour, H., Wang, X., Song, L., \& Hu, Y. (2020). Metal-organic frameworks for flame retardant polymers application: A critical review. Composites Part a-Applied Science and Manufacturing, 139. doi:ARTN 106113 10.1016/j.compositesa.2020.106113.

30. Niu, F. K., Wu, N. J., Yu, J. H., \& Ma, X. B. (2020). Gelation, flame retardancy, and physical properties of phosphorylated microcrystalline cellulose aerogels. Carbohydrate Polymers, 242. doi:ARTN 116422 10.1016/j.carbpol.2020.116422.

31. Pakdel, E., Naebe, M., Kashi, S., Cai, Z., Xie, W., Yuen, A. C. Y., et al. (2020). Functional cotton fabric using hollow glass microspheres: Focus on thermal insulation, flame retardancy, UV-protection and acoustic performance. Progress in Organic Coatings, 141. doi:ARTN 105553

10.1016/j.porgcoat.2020.105553.

32. Prabhakar, M. N., Raghavendra, G. M., Vijaykumar, B. V. D., Patil, K., Seo, J., \& Jung-il, S. (2019). Synthesis of a novel compound based on chitosan and ammonium polyphosphate for flame retardancy applications. Cellulose, 26(16), 8801-8812. doi:10.1007/s10570-019-02671-y.

33. Qian, X. D., Song, L., Hu, Y., \& Jiang, S. H. (2016). Novel DOPO-based epoxy curing agents Synthesis and the structure-property relationships of the curing agents on the fire safety of epoxy resins. Journal of Thermal Analysis and Calorimetry, 126(3), 1339-1348. doi:10.1007/s10973-016-5604-6. 
34. Ramirez-Estrada, A., Mena-Cervantes, V. Y., Mederos-Nieto, F. S., Pineda-Flores, G., \& HernandezAltamirano, R. (2021). Assessment and classification of lignocellulosic biomass recalcitrance by principal components analysis based on thermogravimetry and infrared spectroscopy. International Journal of Environmental Science and Technology. doi:10.1007/s13762-021-03309-y.

35. Salmeia, K. A., Gaan, S., \& Malucelli, G. (2016). Recent Advances for Flame Retardancy of Textiles Based on Phosphorus Chemistry. Polymers, 8(9). doi:ARTN 319 10.3390/polym8090319.

36. Sun, L. S., Qu, Y. T., \& Li, S. X. (2013). Co-microencapsulate of ammonium polyphosphate and pentaerythritol in intumescent flame-retardant coatings. Journal of Thermal Analysis and Calorimetry, 111(2), 1099-1106. doi:10.1007/s10973-012-2494-0.

37. Tang, S., Qian, L. J., Liu, X. X., \& Dong, Y. P. (2016). Gas-phase flame-retardant effects of a bi-group compound based on phosphaphenanthrene and triazine-trione groups in epoxy resin. Polymer Degradation and Stability, 133, 350-357. doi:10.1016/j.polymdegradstab.2016.09.014.

38. Tao, Y., Wang, B., Liu, C., Li, P., Xu, Y. J., Jiang, Z. M., et al. (2021). Cotton/alginate blended knitted fabrics: flame retardancy, flame-retardant mechanism, water absorption and mechanical properties. Cellulose, 28(7), 4495-4510. doi:10.1007/s10570-021-03772-3.

39. van der Veen, I., \& de Boer, J. (2012). Phosphorus flame retardants: Properties, production, environmental occurrence, toxicity and analysis. Chemosphere, 88(10), 1119-1153. doi:10.1016/j.chemosphere.2012.03.067.

40. Velencoso, M. M., Battig, A., Markwart, J. C., Schartel, B., \& Wurm, F. R. (2018). Molecular FirefightingHow Modern Phosphorus Chemistry Can Help Solve the Challenge of Flame Retardancy. Angewandte Chemie-International Edition, 57(33), 10450-10467. doi:10.1002/anie.201711735.

41. Wan, C. Y., Liu, M. S., Liu, S. D., Chen, Y., Zhang, G. X., \& Zhang, F. X. (2021). An efficient and durable DOPO/H3PO4-based flame retardant for cotton fabric. Cellulose. doi:10.1007/s10570-021-03981-w.

42. Wan, C. Y., Liu, M. S., Tian, P. X., Zhang, G. X., \& Zhang, F. X. (2020). Renewable vitamin B5 reactive N$P$ flame retardant endows cotton with excellent fire resistance and durability. Cellulose, 27(3), 17451761. doi:10.1007/s10570-019-02886-z.

43. Wang, Q. W., Lam, J. C. W., Man, Y. C., Lai, N. L. S., Kwok, K. Y., Guo, Y. Y., et al. (2015). Bioconcentration, metabolism and neurotoxicity of the organophorous flame retardant 1,3-dichloro 2propyl phosphate (TDCPP) to zebrafish. Aquatic Toxicology, 158, 108-115. doi:10.1016/j.aquatox.2014.11.001.

44. Wang, Z. Z., Lv, P., Hu, Y., \& Hu, K. L. (2009). Thermal degradation study of intumescent flame retardants by TG and FTIR: Melamine phosphate and its mixture with pentaerythritol. Journal of Analytical and Applied Pyrolysis, 86(1), 207-214. doi:10.1016/j.jaap.2009.06.007.

45. Xing, W. Y., Hu, Y., Song, L., Chen, X. L., Zhang, P., \& Ni, J. X. (2009). Thermal degradation and combustion of a novel UV curable coating containing phosphorus. Polymer Degradation and Stability, 94(7), 1176-1182. doi:10.1016/j.polymdegradstab.2009.02.014.

46. Yang, H. T., Yu, B., Xu, X. D., Bourbigot, S., Wang, H., \& Song, P. G. (2020). Lignin-derived bio-based flame retardants toward high-performance sustainable polymeric materials. Green Chemistry, 22(7), 
2129-2161. doi:10.1039/d0gc00449a.

47. Yu, B., Yuen, A. C. Y., Xu, X. D., Zhang, Z. C., Yang, W., Lu, H. D., et al. (2021). Engineering MXene surface with POSS for reducing fire hazards of polystyrene with enhanced thermal stability. Journal of Hazardous Materials, 401. doi:ARTN 123342 10.1016/j.jhazmat.2020.123342.

48. Yuan, B. H., Hu, Y., Chen, X. F., Shi, Y. Q., Niu, Y., Zhang, Y., et al. (2017). Dual modification of graphene by polymeric flame retardant and $\mathrm{Ni}(\mathrm{OH})(2)$ nanosheets for improving flame retardancy of polypropylene. Composites Part a-Applied Science and Manufacturing, 100, 106-117. doi:10.1016/j.compositesa.2017.04.012.

49. Yuan, H. X., Xing, W. Y., Zhang, P., Song, L., \& Hu, Y. (2012). Functionalization of Cotton with UV-Cured Flame Retardant Coatings. Industrial \& Engineering Chemistry Research, 51(15), 5394-5401. doi:10.1021/ie202468u.

50. Yuan, Y., Wang, W., Shi, Y. Q., Song, L., Ma, C., \& Hu, Y. (2020). The influence of highly dispersed Cu2Oanchored MoS2 hybrids on reducing smoke toxicity and fire hazards for rigid polyurethane foam. Journal of Hazardous Materials, 382. doi:ARTN 121028 10.1016/j.jhazmat.2019.121028.

51. Zabihi, O., Ahmadi, M., Li, Q. X., Ferdowsi, M. R. G., Mahmoodi, R., Kalali, E. N., et al. (2020). A sustainable approach to scalable production of a graphene based flame retardant using waste fish deoxyribonucleic acid. Journal of Cleaner Production, 247. doi:ARTN 119150 10.1016/j.jclepro.2019.119150.

52. Zeng, S. L., Xing, C. Y., Chen, L., Xu, L., Li, B. J., \& Zhang, S. (2020). Green flame-retardant flexible polyurethane foam based on cyclodextrin. Polymer Degradation and Stability, 178. doi:ARTN 109171 10.1016/j.polymdegradstab.2020.109171.

53. Zhang, L. Y., Xue, W., \& Gu, L. M. (2020a). Study on properties and application of pyrophosphate flame retardant microcapsules prepared from hemicellulose maleate. Cellulose, 27(7), 3931-3946. doi:10.1007/s10570-020-03045-5.

54. Zhang, M. M., Buekens, A., \& Li, X. D. (2016a). Brominated flame retardants and the formation of dioxins and furans in fires and combustion. Journal of Hazardous Materials, 304, 26-39. doi:10.1016/j.jhazmat.2015.10.014.

55. Zhang, P. K., Fan, H. J., Hu, K., Gu, Y. M., Chen, Y., Yan, J., et al. (2018). Solvent-free two-component polyurethane conjugated with crosslinkable hydroxyl-functionalized ammonium polyphosphate: Curing behaviors, flammability and mechanical properties. Progress in Organic Coatings, 120, 88-99. doi:10.1016/j.porgcoat.2018.01.019.

56. Zhang, T. L., Kuga, S., Wu, M., \& Huang, Y. (2020b). Chitin Nanofibril-Based Flame Retardant for Paper Application. Acs Sustainable Chemistry \& Engineering, 8(33), 12360-12365.

doi:10.1021/acssuschemeng.0c02016.

57. Zhang, T. L., Wu, M., Kuga, S., Ewulonu, C. M., \& Huang, Y. (2020c). Cellulose Nanofibril-Based Flame Retardant and Its Application to Paper. Acs Sustainable Chemistry \& Engineering, 8(27), 1022210229. doi:10.1021/acssuschemeng.0c02892. 
58. Zhang, X. M., Suhring, R., Serodio, D., Bonnell, M., Sundin, N., \& Diamond, M. L. (2016b). Novel flame retardants: Estimating the physical-chemical properties and environmental fate of 94 halogenated and organophosphate PBDE replacements. Chemosphere, 144, 2401-2407. doi:10.1016/j.chemosphere.2015.11.017.

59. Zhang, Y., Tian, W. X., Liu, L. X., Cheng, W. H., Wang, W., Liew, K. M., et al. (2019). Eco-friendly flame retardant and electromagnetic interference shielding cotton fabrics with multi-layered coatings. Chemical Engineering Journal, 372, 1077-1090. doi:10.1016/j.cej.2019.05.012.

60. Zhao, S. P., Pei, L., He, J., Zhang, X., Hu, W. H., Yan, H., et al. (2021). Curing mechanism, thermal and ablative properties of hexa-(4-amino-phenoxy) cyclotriphosphazene/benzoxazine blends. Composites Part B-Engineering, 216. doi:ARTN 108838 10.1016/j.compositesb.2021.108838.

61. Zheng, Z. H., Liu, Y. H., Dai, B. Y., Meng, C. Y., \& Guo, Z. X. (2019). Fabrication of cellulose-based halogen-free flame retardant and its synergistic effect with expandable graphite in polypropylene. Carbohydrate Polymers, 213, 257-265. doi:10.1016/j.carbpol.2019.02.088.

62. Zhu, W. J., Hao, S. S., Yang, M. Y., Cheng, B. W., \& Zhang, J. M. (2020). A synergistic flame retardant of glycosyl cross-linking boron acid and ammonium salt of phytic acid to enhance durable flame retardancy of cotton fabrics. Cellulose, 27(16), 9699-9710. doi:10.1007/s10570-020-03417-x.

\section{Figures}
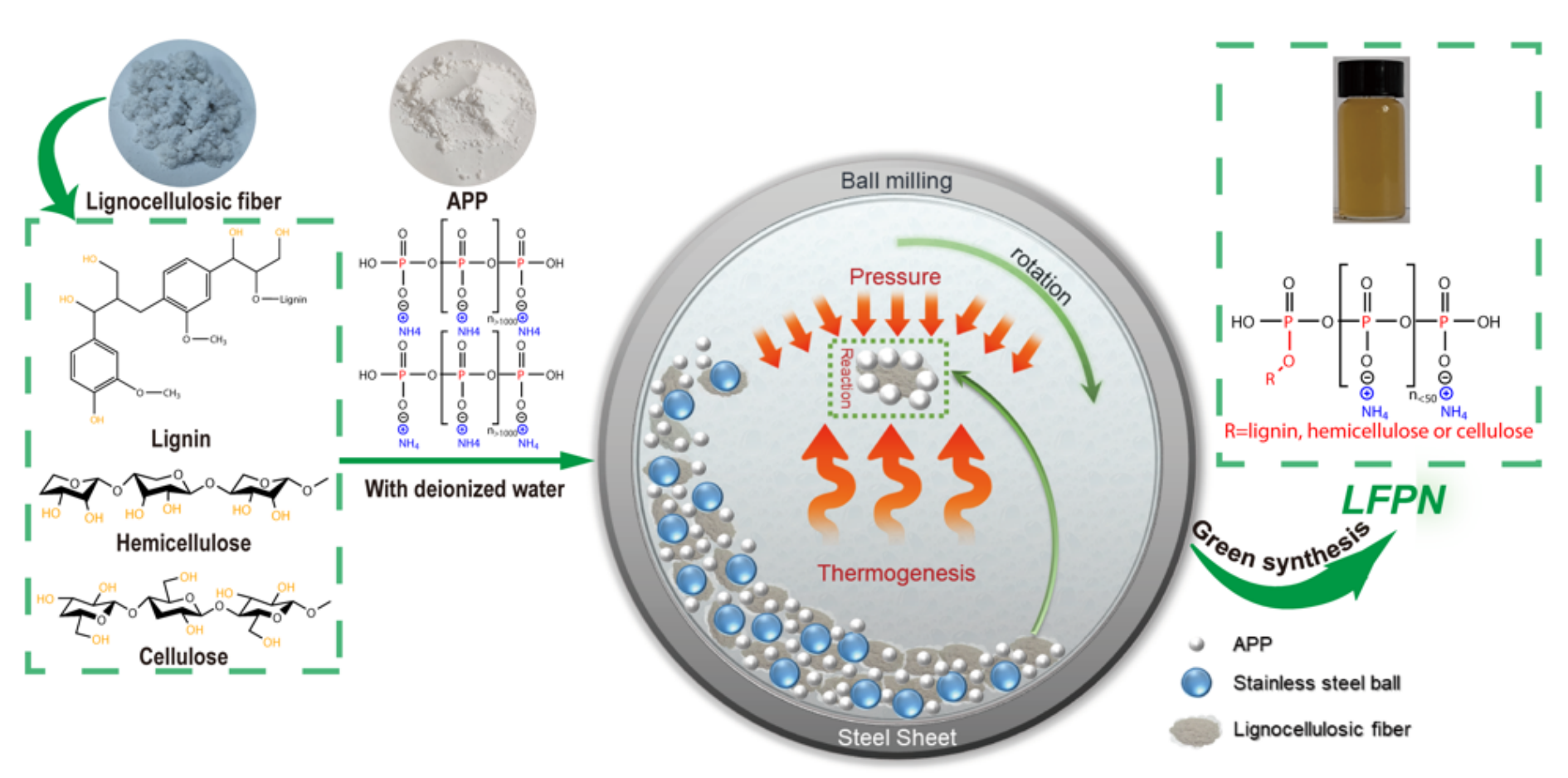

Figure 1

Schematic diagram of synthesis of lignocellulosic fibre-based P-N flame retardant. 


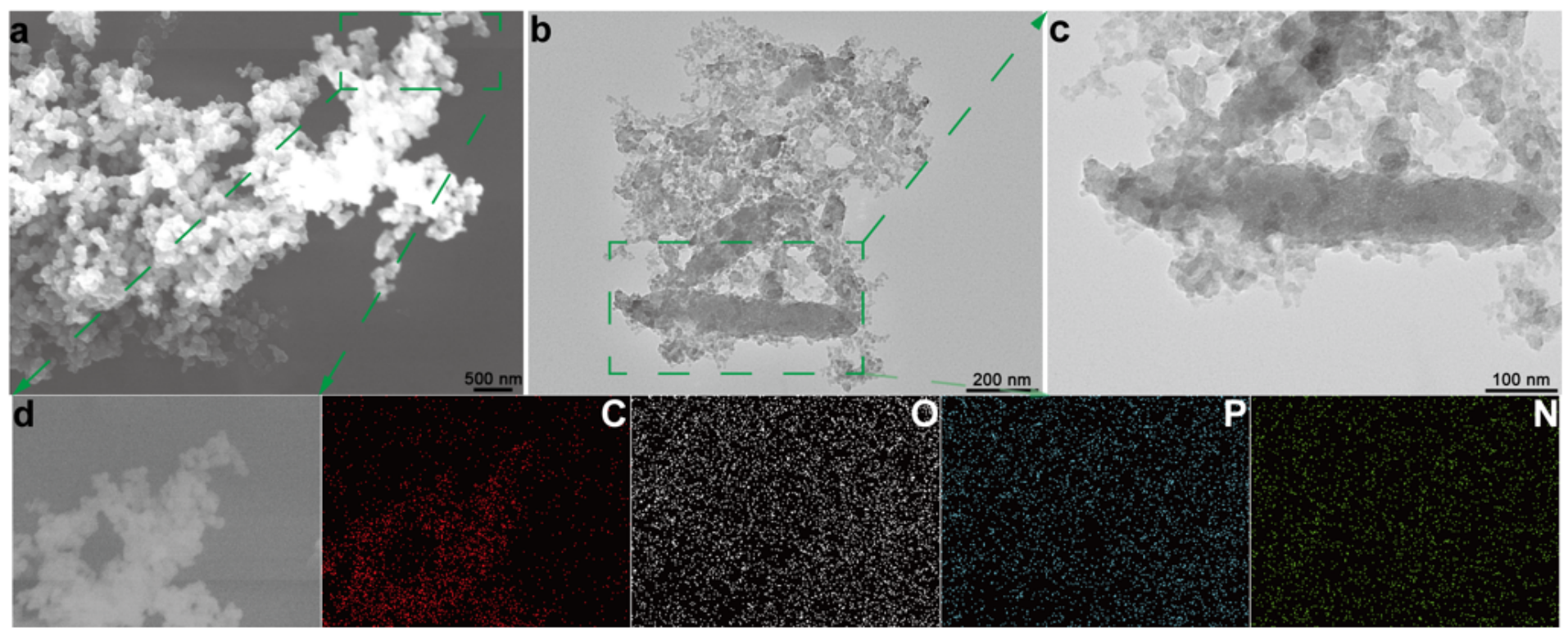

Figure 2

SEM image of LFPN (a), TEM of LFPN (b, c) and SEM-EDS of LFPN (d).
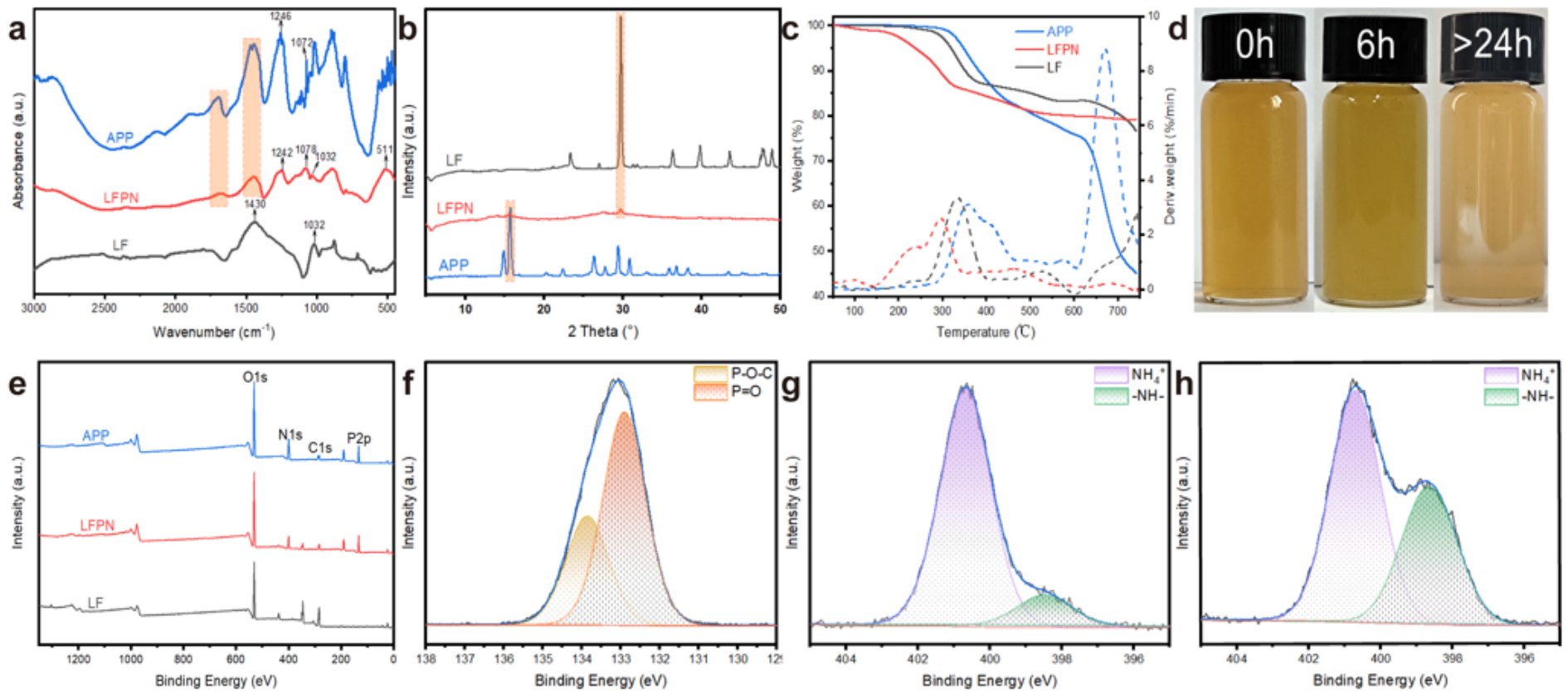

Figure 3

FTIR spectra (a), XRD pattern (b) and TGA curves (c) of APP, LF and LFPN; Dispersion stability test images of LFPN in water (d); Full XPS spectra (e) of APP, LF and LFPN; High resolution element spectra of P2p (f) and N1s (g) of LFPN; High resolution element spectra of N1s (h) of APP. 


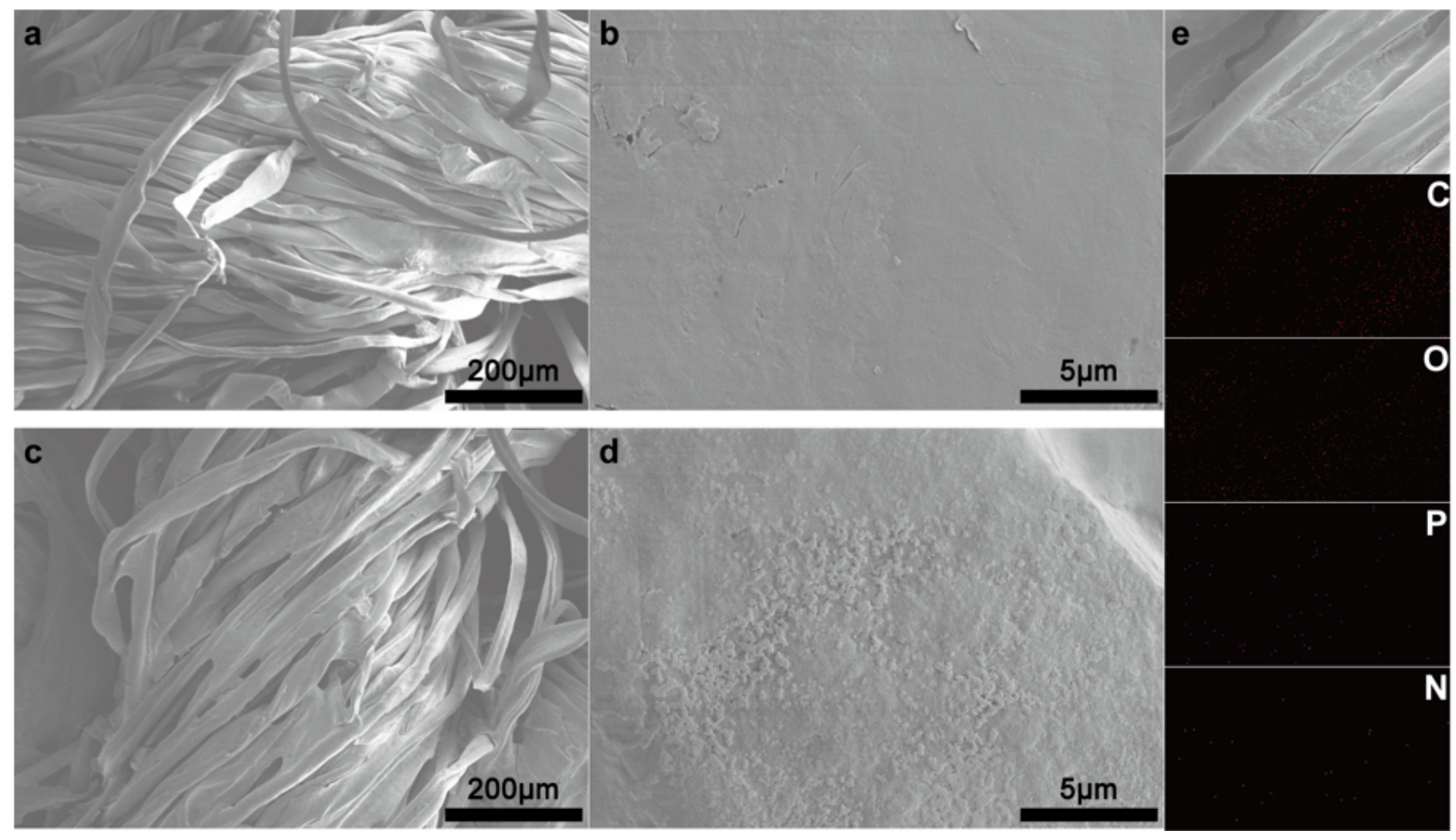

Figure 4

SEM image of Cotton (a, b) and Cotton-LFPN (c, d); SEM-EDS of Cotton-LFPN (e).
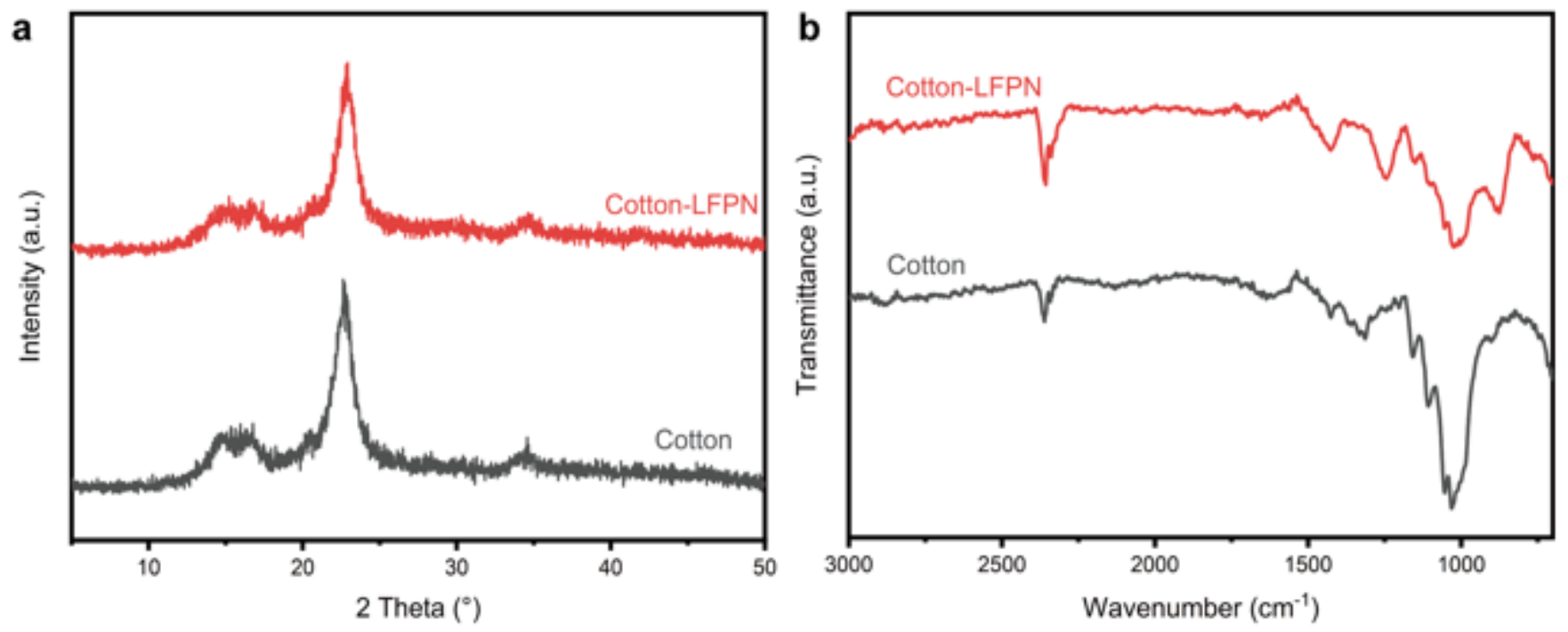

Figure 5

XRD pattern (a) and FTIR spectra (b) of Cotton and Cotton-LFPN. 

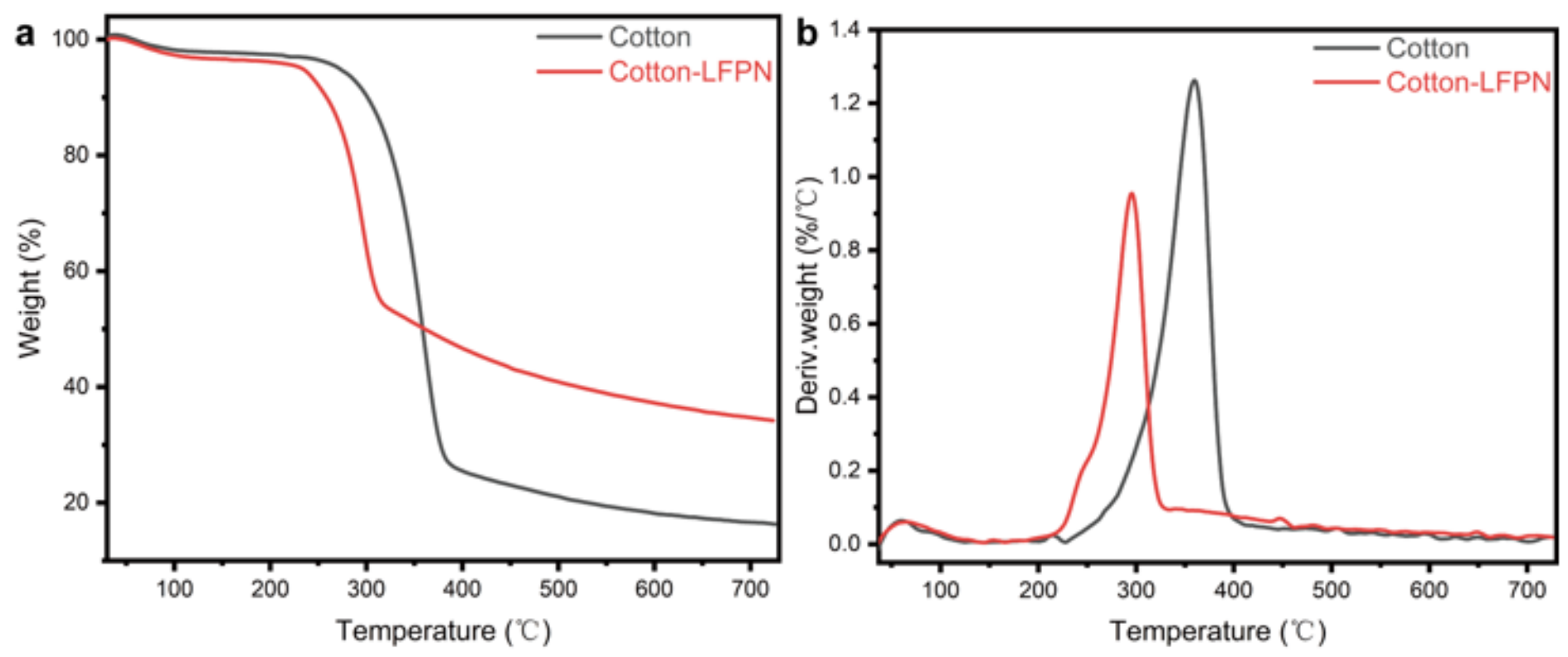

Figure 6

TGA (a) and DTG (b) curves in the nitrogen of Cotton and Cotton-LFPN. 
a
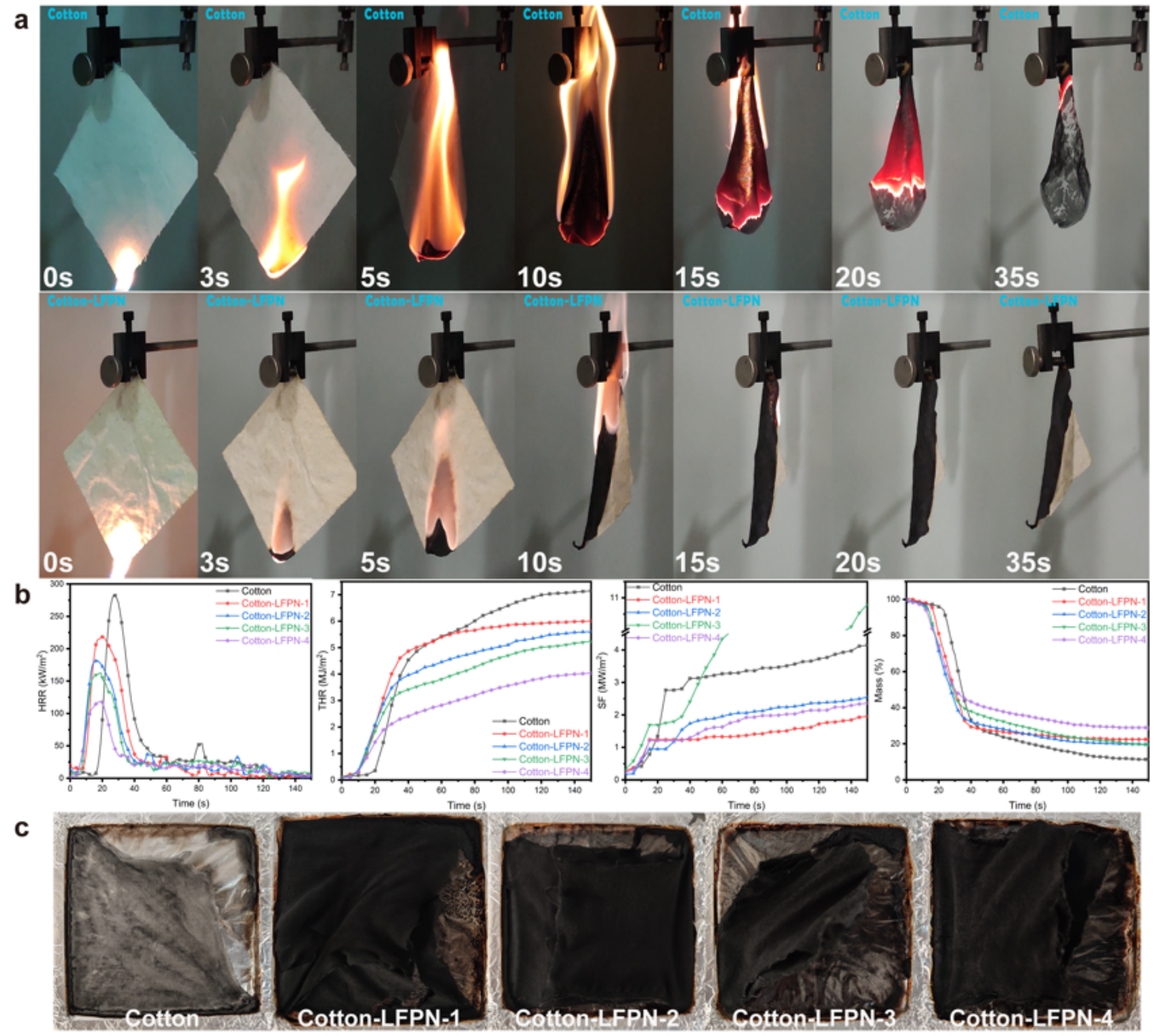

Figure 7

Flammability test (a), cone calorimeter test (b) and digital images of char (c) after CCT of Cotton-LFPN. 

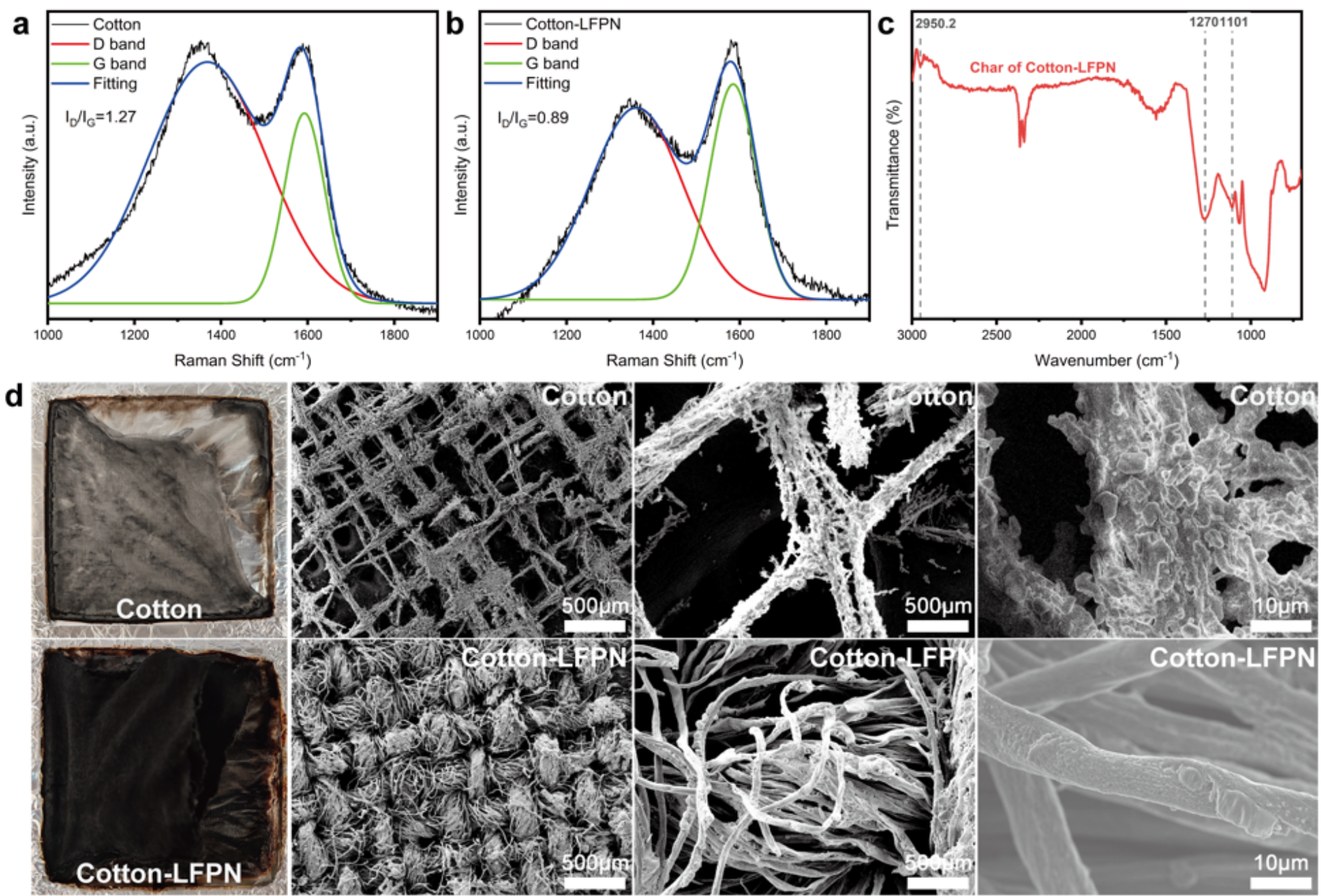

Cotton-LFPN

Figure 8

Condensed phase analysis LRS (a, b), ATR-FTIR (c), and SEM (d) of char residues of Cotton and CottonLFPN.
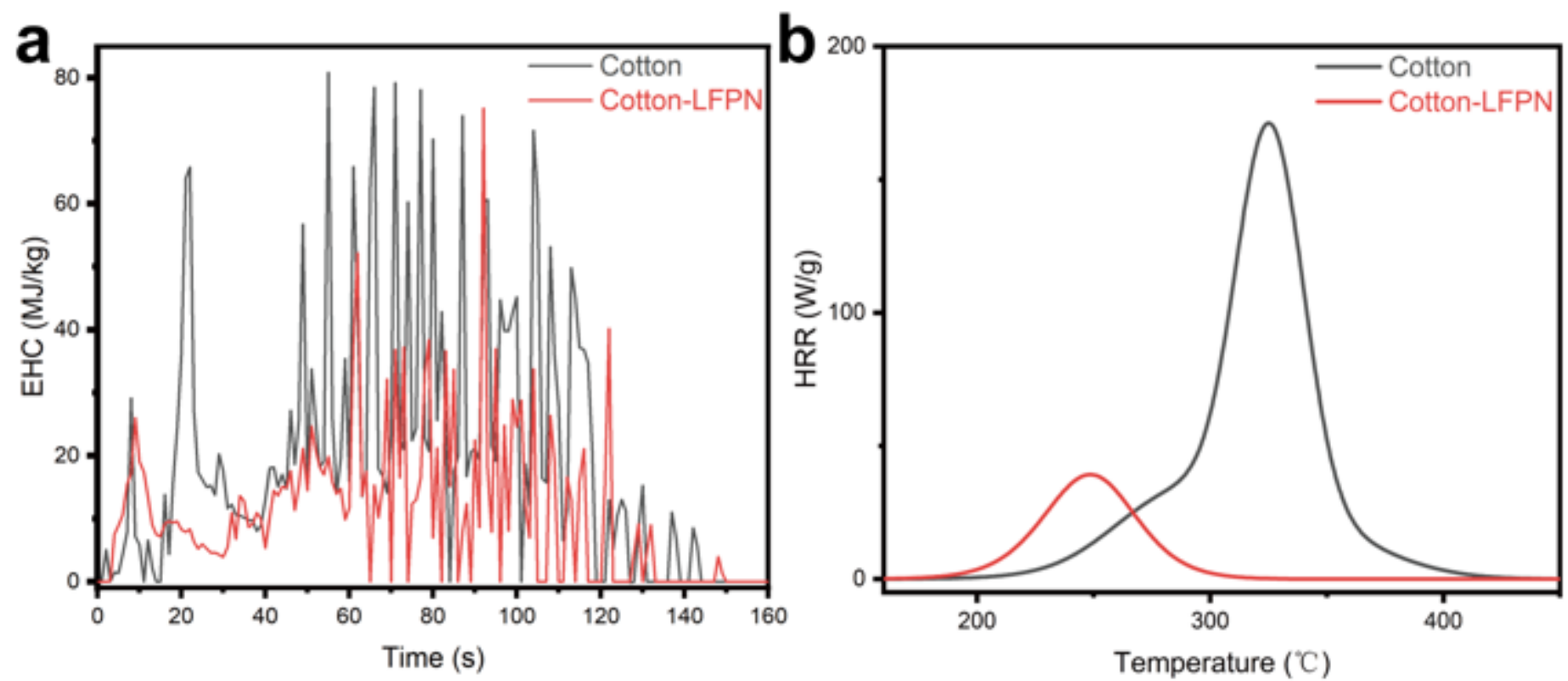
Figure 9

EHC curves (a) and MCC (b) of Cotton and Cotton-LFPN.
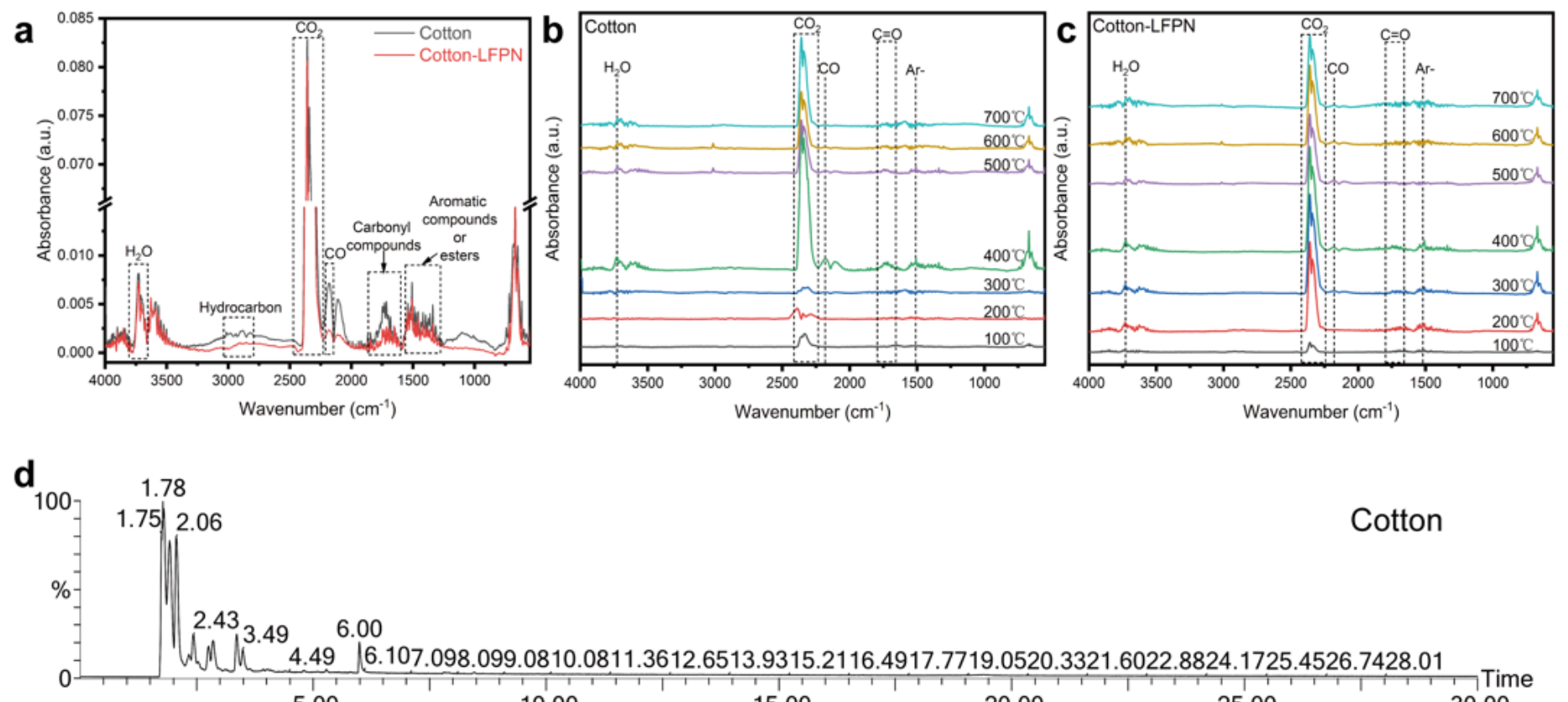

.06

Cotton

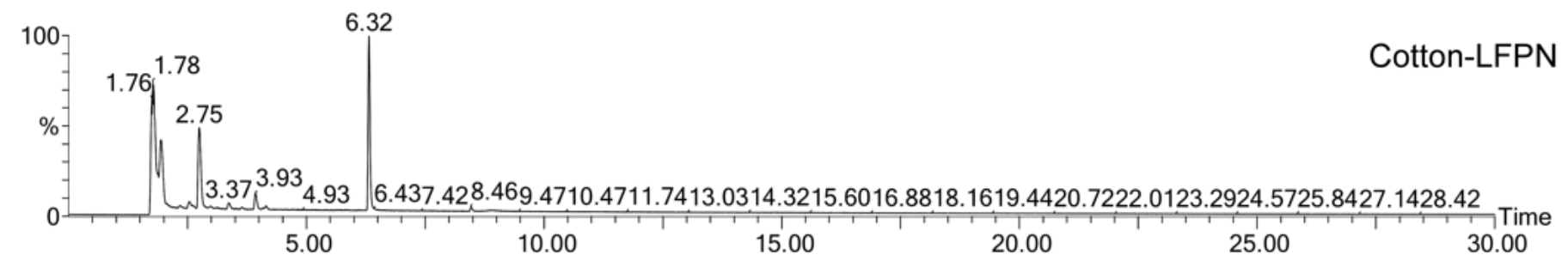

Figure 10

TG-IR spectra of pyrolysis products of Cotton and Cotton-LFPN (a) at maximum decomposition rate, the TG-IR spectra at specific temperature $(b, c)$, gas chromatogram of pyrolysis products of Cotton and Cotton-LFPN at maximum decomposition rate. 


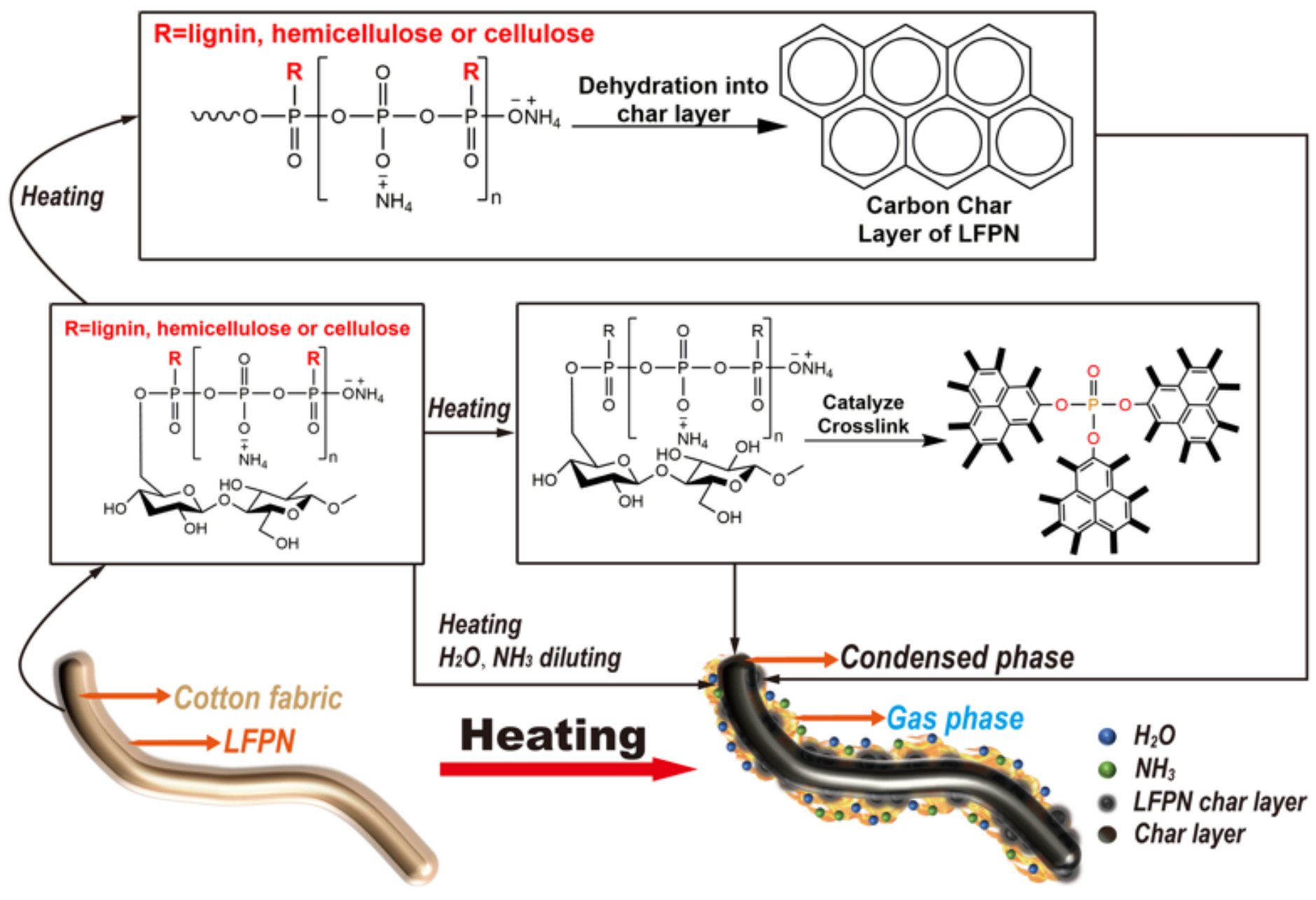

Figure 11

Schematic illustration for flame retardant mechanism of Cotton-LFPN.

\section{Supplementary Files}

This is a list of supplementary files associated with this preprint. Click to download.

- SupportingInformation.docx

- Video.mp4 